\title{
Trends in antimicrobial resistance of bacterial pathogens in Harare, Zimbabwe, 2012-2017: a secondary dataset analysis
}

Marvellous Mhondoro ${ }^{1}$, Nqobile Ndlovu ${ }^{2 *}$, Bangure Donewell ${ }^{3}$, Tsitsi Juru ${ }^{1 *}$ (D), Gombe Notion Tafara ${ }^{1}$, Shambira Gerald ${ }^{1}$, Nsubuga Peter ${ }^{4}$ and Tshimanga Mufuta ${ }^{1}$

\begin{abstract}
Background: Antimicrobial resistance is one of the most serious public health threats of the twenty-first century. The implementation of AMR surveillance in Zimbabwe is limited. However, data from a private laboratory in Harare revealed increasing resistance rates to common antibiotics like ampicillin (i.e., from 73.9\% in 2011 to 74.6\% in 2015). The increasing resistance rates indicate that Zimbabwe is affected by AMR. This study was done to determine the magnitude of AMR in Harare and determine the trends of AMR to first-line and to last-resort antibiotics and make recommendations to mitigate the problem.
\end{abstract}

Methods: A retrospective record review of data collected from the microbiology department at a private laboratory between January 2012 and December 2017 was done. The outcome of interest was the antibiotic susceptibility of bacterial isolates. Microsoft Excel 2016 was used to plot trends from 2012 to 2017 and Epi Info ${ }^{\text {TM7 }}$ was used for statistical analysis.

Results: A total of 23,432 isolates, of 12 medically important bacteria were analysed. Forty-three percent of the isolates were from urines, $36.7 \%$ were from pus swabs and $7 \%$ were from blood. The most common pathogen was Escherichia coli (43.2\%), followed by Staphylococcus aureus (15.8\%) and the least common was Neisseria gonorrhoea (0.2\%). Resistance was highest to ampicillin followed by penicillin, both ranging between 70 and $100 \%$ over the six years. Statistically significant increases in resistance to commonly used antibiotics were observed in amoxicillin-resistant E. coli and Streptococcus pneumonia and third generation cephalosporinresistant E. coli. There was an increase in resistance to last-line antibiotics i.e., fluoroquinolone-resistant Salmonella spp. and carbapenem-resistant Pseudomonas aeruginosa and Acinetobacter baumannii. However, methicillin-resistant $S$. aureus showed a decreasing trend.

Conclusions: There is a high burden of drug resistance to common antibiotics in Harare and an emergence of resistance to last-line antibiotics.

Keywords: Antimicrobial agents, Antibiotic, Resistance

\footnotetext{
* Correspondence: nqndlovu@yahoo.com; tsitsijuru@gmail.com

${ }^{2}$ African Society of Laboratory Medicine, Addis Ababa, Ethiopia

${ }^{1}$ Department of Community Medicine, University of Zimbabwe, Harare,

Zimbabwe

Full list of author information is available at the end of the article
}

(c) The Author(s). 2019 Open Access This article is distributed under the terms of the Creative Commons Attribution 4.0 International License (http://creativecommons.org/licenses/by/4.0/), which permits unrestricted use, distribution, and reproduction in any medium, provided you give appropriate credit to the original author(s) and the source, provide a link to the Creative Commons license, and indicate if changes were made. The Creative Commons Public Domain Dedication waiver (http://creativecommons.org/publicdomain/zero/1.0/) applies to the data made available in this article, unless otherwise stated. 


\section{Background}

Antimicrobial resistance (AMR) is one of the most serious public health threats of the twenty-first century [1]. Globally, about 700,000 people die due to AMR related illnesses every year. It is estimated that by 2050 these deaths will reach10 million, costing the world US\$100 trillion [2]. In 2014, the World Health Organisation (WHO) reported $>25 \%$ resistance to penicillin by Streptococcus pneumoniae in all its six regions. Five out of the six regions reported $>50 \%$ resistance to 3 rd generation cephalosporins by Eschericia coli. In Africa, AMR surveillance is limited, but the available data suggest up to $100 \%$ resistance to beta-lactam antibiotics [3]. WHO reported resistance to last resort antibiotics like vancomycin, 3rd generation cephalosporins, clindamycin and carbapenems by some organisms. Resistance to these last line antibiotics led the WHO to advocate for research and development of more antimicrobials for treatment of these priority organisms in 2017 [4]. In response to this global threat, Africa Centres for Disease Control (CDC) launched the Antimicrobial Resistance Surveillance Network (AMRSNET) which works closely with WHO to strengthen AMR surveillance in Africa [5].

The 2014 WHO global report on AMR showed large gaps in the surveillance of drug resistance in many countries including Zimbabwe [3]. Program focussed AMR surveillance was done in Zimbabwe for malaria, Human Immunodeficiency Virus (HIV) and tuberculosis (TB) but there is a huge knowledge deficit on AMR to common bacterial infections. The overall burden of AMR and its effects on the country's economy are unknown. Available data for AMR by common bacteria are from studies by academics. A study by Mbanga et al. in 2010 showed high resistance to antibiotics by uro-pathogens e.g., ampicillin (84.5\%) and cotrimoxazole (68.5\%) [6]. Other studies show AMR in diseases like typhoid and tuberculosis $[7,8]$. Drug resistance undermines health delivery programs and threatens the achievement of several United Nations Sustainable Development Goals (SDGs), particularly the targets for good health and wellbeing (i.e., SDG 3) [9].

Data from a reputable technologically advanced Zimbabwean laboratory, accredited by the South African National Accreditation System (SANAS), showed an increasing trend in resistance to the most common antibiotics for example, $73.9 \%$ of the isolates were resistant to amoxicillin in 2011 and rose to $74.6 \%$ in 2015 . The data set is primarily for record keeping of patients' results. It is used by microbiologists to monitor the antimicrobial susceptibility trends and advise clients (i.e., submitting clinicians) on the effective treatment options.

A retrospective record review on the data was done to describe the trends in antimicrobial resistance by key bacterial organisms and to determine the burden of resistance to last resort antibiotics, to explore reasons for the prevailing trends and provide useful information to clinicians and policy makers.

\section{Methods \\ Aim}

The aim of the study was to determine the trends in antibiotic resistance to routinely used antibiotics.

\section{Study design}

A retrospective record review of a data set obtained from microbiology laboratory results was done.

\section{Study setting}

The study was conducted between January and March 2018 using data from a private clinical laboratory in Harare. The laboratory is one of the major diagnostic laboratories in Zimbabwe with more than 50 tests accredited by SANAS in accordance with recognised international standard ISO 15189:2012. The laboratory's main catchment area is Harare city, with a population of approximately two million people basing on the 2012 census [10]. The accredited microbiology tests include microscopy, culture, identification and antibiotic sensitivity tests. There is an adequate staff complement of proficient scientists with great capacity for quality testing and an information system to store and manage data. The microbiology department receives specimen for microscopy, culture and sensitivity from both private and public health institutions.

\section{Data source}

The data were obtained from a dataset known as "organisms isolated" which stores information from the microbiology department. The data set was created in 2010, and it is embedded in an internationally recognised laboratory information management system called Meditech. Records from 1 January 2012 up to 31 December 2017 were analysed.

The data set consists of at least 65 bacteria species. A purposive sampling of 12 medically important bacteria species was done. They include Acinetobacter baumannii, Coagulase-negative Staphylococcus, Enterobacter species, Enterococcus species, Klebsiella pnemoniae, Escherichia coli, Staphylococcus aureus, Pseudomonas aeruginosa, Salmonella species, Campylobacter species, Neisseria gonorrhoea and Streptococcus pneumonia. Identification of the bacteria was achieved by culturing different specimens onto appropriate media and incubating at $36^{\circ} \mathrm{C}$. The isolated bacteria were identified by Analytical Profile Index (BioMerieux, USA), Microscan system (Beckman Coulter, CA, USA), antisera and biochemical tests (e.g., coagulase and sugars). The laboratory used Kirby-Bauer disk diffusion method on Muller Hinton agar or Microscan system for antibiotic sensitivity testing. A saline suspension of an 
isolate was standardised using Densicheck plus instrument (BioMerieux, USA) to achieve inoculum density equivalent to McFarlane standard before sensitivity testing. Antibiotic discs were then placed onto the plated agar (not more than 7 discs per plate) and incubated overnight at $36^{\circ} \mathrm{C}$ and Clinical and Laboratory Standards Institute guidelines were used for interpreting the susceptibility patterns.

\section{Data management and analysis}

A total of 23,904 patients had at least one organism isolated from the samples. Isolates from the 12 above mentioned organisms were included in the study. For specimens with more than one isolate, only the first recorded isolate was included. All isolates not mentioned above were excluded. If a patient had two identical bacteria isolated less than a month apart, the second one was excluded from analysis. A total of 472 isolates were excluded from the analysis hence the final sample size was 23,432 isolates. The variables analysed included the specimen type (i.e., urines, blood, pus/ swabs, penile swabs, seminal fluid, urethral, vaginal, high vaginal, vulval swab, ear, nasal and throat swabs, cerebrospinal fluid and stools), organisms isolated and antibiotics tested (i.e., ampicillin, amoxicillin, augmentin, ciprofloxacin, cotrimoxazole, ceftriaxone, penicillin, gentamicin, carbapenems, vancomycin). The outcome of interest was the antibiotic susceptibility of the isolates. For statistical analysis, isolates were classified as either susceptible or resistant to an antimicrobial and all isolates with intermediate reactions were classified as resistant.

Data quality was checked using completeness of data entries in the Laboratory Information System. Resistance to each antibiotic was analysed separately, using Microsoft Excel 2016 to plot the trends from 2012 to 2017. Simple linear regression was employed to test the significance of antibiotic resistance trends over time. Epi-Info ${ }^{\text {tax }}$ 7- (CDC, Atlanta, Georgia) statistical package was used for statistical analysis. The $p$-values $<0.05$ were considered statistically significant.

\section{Results}

Distribution of specimen and bacterial isolates analysed, Harare 2012-17

All records were $100 \%$ complete for the variables analysed. Urine was the most common specimen type accounting for $43.4 \%$ (10167), followed by pus-swabs and blood which accounted for $36.7 \%$ (8588) and $7.4 \%$ (1730) respectively. The least common specimen type was cerebrospinal fluid (0.1\%). From these specimens, E. coli was the most frequent isolate accounting for 43.2\% (10130), followed by $S$. aureus and the least frequent was $N$. gonorrhoea which accounted for $0.2 \%$ (53) of the isolates (Table 1).
Table 1 Distribution of specimen and bacterial isolates analysed, Harare 2012-17

\begin{tabular}{|c|c|c|c|}
\hline Variable & Category & $\begin{array}{l}\text { Frequency } \\
(n=23,432)\end{array}$ & Percentage (\%) \\
\hline \multirow[t]{15}{*}{ Specimen type } & Urine & 10,167 & 43.4 \\
\hline & Pus swab & 8588 & 36.7 \\
\hline & Blood & 1730 & 7.4 \\
\hline & Sputum & 1118 & 4.8 \\
\hline & Ear* & 586 & 2.5 \\
\hline & Nose* & 267 & 1.1 \\
\hline & Throat* & 95 & 0.4 \\
\hline & Penile swab & 25 & 0.1 \\
\hline & Seminal fluid & 54 & 0.2 \\
\hline & Urethral & 125 & 0.5 \\
\hline & Vaginal & 117 & 0.5 \\
\hline & High vaginal swab** & 134 & 0.6 \\
\hline & Vulval swab** & 19 & 0.1 \\
\hline & Stool & 384 & 1.6 \\
\hline & Cerebrospinal fluid & 23 & 0.1 \\
\hline \multirow[t]{13}{*}{ Bacteria species } & E. coli & 10,130 & 43.2 \\
\hline & S. aureus & 3703 & 15.8 \\
\hline & Coag neg & 2599 & 11.1 \\
\hline & staphylococcus & & \\
\hline & Enterococcus spp & 1891 & 8.1 \\
\hline & P. areuginosa & 1649 & 7 \\
\hline & K. pneumoniae & 1299 & 5.5 \\
\hline & Enterobacter spp & 834 & 3.6 \\
\hline & A.baumanii & 616 & 2.6 \\
\hline & Salmonella spp & 384 & 1.6 \\
\hline & S.pneumoniae & 137 & 0.6 \\
\hline & Campylobacter spp & 137 & 0.6 \\
\hline & N. gonorrhoea & 53 & 0.2 \\
\hline
\end{tabular}

*ENT- ear, nose and throat

**STI- sexually transmitted infections

\section{Trends of total antimicrobial resistance by common antibiotics, Harare 2012-17}

Ninety-five percent of all bacteria analysed were resistant to penicillin in 2012. The resistance decreased to $71.4 \%$ in 2014 and by 2017 it had increased again to $98.7 \%$. Resistance to amoxicillin decreased from 85.9 to $75.8 \%$ between 2012 and 2016 before increasing to $87.7 \%$ in 2017. Total resistance to cotrimoxazole was constantly high, ranging between 58 and $62 \%$ throughout the study period. Over the 6 years there was increasing resistance to ceftriaxone $\left(\mathrm{R}^{2}=0.90 ; p<0.01\right)$ and augmentin $\left(\mathrm{R}^{2}=\right.$ $0.90 ; p<0.01$ ) (Fig. 1). Resistance to ciprofloxacin (not shown in the figure) showed a slight increase from $28.9 \%$ in 2012 to $37.8 \%$ in 2017 . 


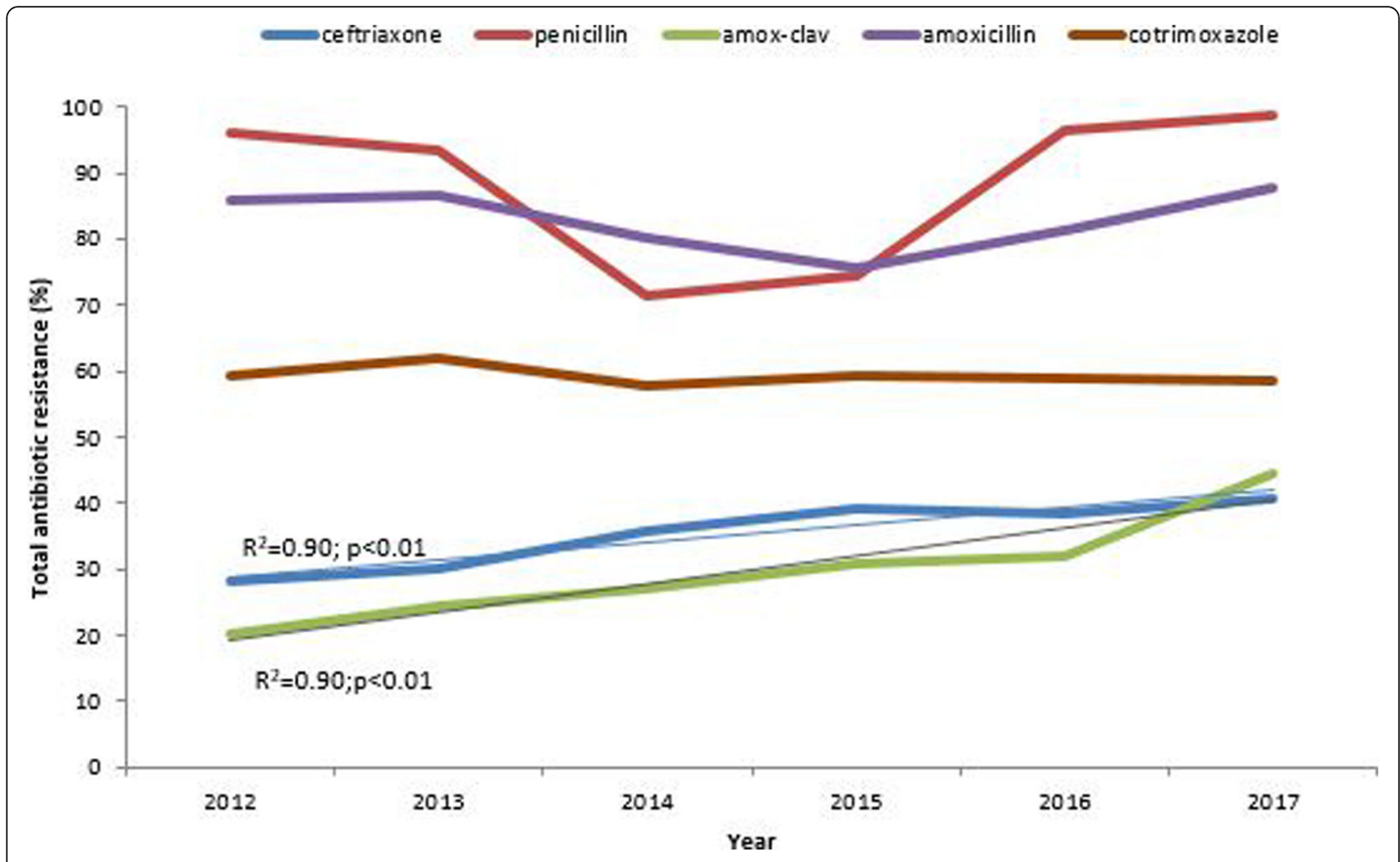

Fig. 1 Trends of total antimicrobial resistance by common antibiotics, Harare 2012-17

Trends of resistance to common antibiotics by specific organisms, Harare 2012-17

The trends of resistance to different antibiotics by specific organisms between 2012 and 2017 are summarised in Table 2.

Resistance to amoxicillin was highest among Gramnegative bacteria. $E$. coli had high resistance to amoxicillin throughout the six years i.e., $96.2 \%$ in 2012 and decreased to a minimum of $84.1 \%$ in 2015 then increased again to $97.4 \%$ in $2017\left(R^{2}=0.07 ; p=0.59\right)$. S. pneumoniae showed increasing resistance to amoxicillin (i.e., 4.35 to $56.3 \%$ ) between 2012 and 2017: the trend was statistically significant with $\mathrm{R}^{2}=0.83 ; p=0.01$.

Resistance to augmentin by E.coli was statistically significant i.e., $20.1 \%$ in 2012 to $40.2 \%$ in $2017\left(R^{2}=0.98\right.$; $p<0.01)$. S. pneumoniae also showed increasing resistance to augmentin i.e., from $0 \%$ in 2012 to a $71.4 \%$ peak in 2016 and then a decrease to $55.5 \%$ in $2017\left(R^{2}=0.87\right.$; $p<0.01)$. S. aureus showed declining resistance to augmentin from 6.8 to $2.0 \%$ between 2012 and $2017\left(\mathrm{R}^{2}=\right.$ $0.79 ; p=0.02)$ Fig. 2.

\section{Trends of resistance to cephalosporins by specific} organisms, Harare 2012-17

Resistance to cephalosporins by $E$. coli increased from $20.3 \%$ in 2012 to $34.9 \%$ in $2017\left(R^{2}=0.89 ; p<0.01\right)$ while a decrease was noted in Acinetobacter baumannii from 69.1 to $29.8 \%\left(\mathrm{R}^{2}=0.89 ; p<0.01\right)$. Pseudomonas aeruginosa and Salmonella spp. both showed $<15 \%$ resistance to 3 rd generation cephalosporins (i.e., ceftazidime) between 2012 and 2017 (Fig. 3). N. gonorrhoea and $S$. pneumoniae were susceptible to ceftriaxone with $0 \%$ resistance over the study period (data not shown).

\section{Antimicrobial resistance trends WHO priority organisms, Harare 2012-17}

There was an emergence of carbapenem resistance over the past six years. In 2012 carbapenem resistance was less than $2 \%$ for both $A$. baumannii and $P$. aeruginosa but by 2017 it had increased to $15.4 \%\left(\mathrm{R}^{2}=0.69 ; p=\right.$ $0.04)$ and $2.9 \%\left(R^{2}=0.573 p\right.$ value $\left.=0.08\right)$ respectively. Carbapenem resistant Enterobacteriaceae was $<1 \%$ between 2012 and 2017 (Fig. 4). There was also an increase in extended spectrum beta-lactamase production in Enterobacteriaceae (i.e., E. coli and Enterobacter spp) over the years. Enterobacter spp. showed a statistically significant trend $\left(\mathrm{R}^{2}=0.95 ; p<0.01\right)$.

There was a decrease in methicillin-resistant $S$. aureus (MRSA) from 6.9\% in 2012 to $2.3 \%$ in $2017\left(\mathrm{R}^{2}=\right.$ $0.80 ; p=0.01)$. A peak resistance of $8.5 \%$ was recorded in 2013. Fluoroquinolone-resistant Salmonella species showed an increasing but fluctuating trend over the six 
Table 2 Summary of antibiotic resistance trends, Harare 2012-2017

\begin{tabular}{|c|c|c|c|c|c|c|c|}
\hline \multirow[t]{2}{*}{ Antibiotic } & \multirow[t]{2}{*}{ Bacteria } & \multicolumn{6}{|c|}{ Yearly Resistance rates } \\
\hline & & 2012 & 2013 & 2014 & 2015 & 2016 & 2017 \\
\hline \multirow[t]{2}{*}{ Amoxicillin } & E.coli & 96.2 & 98.9 & 88.9 & 84.1 & 88.6 & 97.4 \\
\hline & S. pneumoniae & 4.4 & 10.3 & 11.1 & 54.6 & 56.5 & 56.3 \\
\hline \multirow[t]{3}{*}{ Augmentin } & E.coli & 20.1 & 23.7 & 29.7 & 35.1 & 36.8 & 40.2 \\
\hline & S. pneumoniae & 5.2 & 15.2 & 33.3 & 44.5 & 71.4 & 55.6 \\
\hline & S. aureus & 6.8 & 8.3 & 7.3 & 4.2 & 3.8 & 2.0 \\
\hline \multirow[t]{6}{*}{ 3rd gen cephalosporins } & E.coli & 20.3 & 23.5 & 29.6 & 33.2 & 32.2 & 34.9 \\
\hline & A.baumannii & 69.1 & 60.7 & 61.3 & 37.5 & 40.9 & 29.8 \\
\hline & P. aeruginosa & 11.4 & 12.9 & 12.1 & 12.1 & 13.8 & 9.2 \\
\hline & Salmonella spp & 7.6 & 2.7 & 5.4 & 10.7 & 9.4 & 6.3 \\
\hline & N. gonorrhoea & 0 & 0 & 0 & 0 & 0 & 0 \\
\hline & S. pneumonia & 0 & 0 & 0 & 0 & 0 & 0 \\
\hline \multirow[t]{3}{*}{ Meropenem } & A.baumannii & 1.8 & 6.9 & 9.1 & 4.4 & 17.0 & 15.4 \\
\hline & P.aeruginosa & 1.4 & 0.5 & 0.4 & 0.7 & 2.9 & 2.9 \\
\hline & Ecoli & 0 & 0 & 0 & 0.1 & 0.2 & 0 \\
\hline Methicillin & S. aureus & 6.9 & 8.5 & 7.1 & 4.0 & 3.7 & 2.3 \\
\hline \multirow[t]{2}{*}{ Fluoroquinolones } & Salmonella spp & 2.7 & 0 & 0 & 2.6 & 7.7 & 6.5 \\
\hline & Campylobacter spp & 35.3 & 35.0 & 46.4 & 45.0 & 63.6 & 40.0 \\
\hline
\end{tabular}

years, the lowest resistance rates were recorded between 2013 and 2014 with a peak of $7.7 \%$ in 2016 and a slight decline to $6.5 \%$ in $2017\left(\mathrm{R}^{2}=0.55 p=0.09\right)$. Fluoroquinolone resistance was high among Campylobacter species; it increased from $35.3 \%$ to a peak of 63.6\% in 2016 and decreased to $40 \%$ in $2017\left(R^{2}=0.30\right.$ $p=0.27$ ) (Fig. 5).

\section{Discussion}

Several statistically significant changes in antibiotic resistance rates were observed between January 2012 and December 2017. The most important trends were the high resistance rates to commonly used antibiotics and the emerging resistance to last treatment options. According to the AMR situational analysis of 2007,

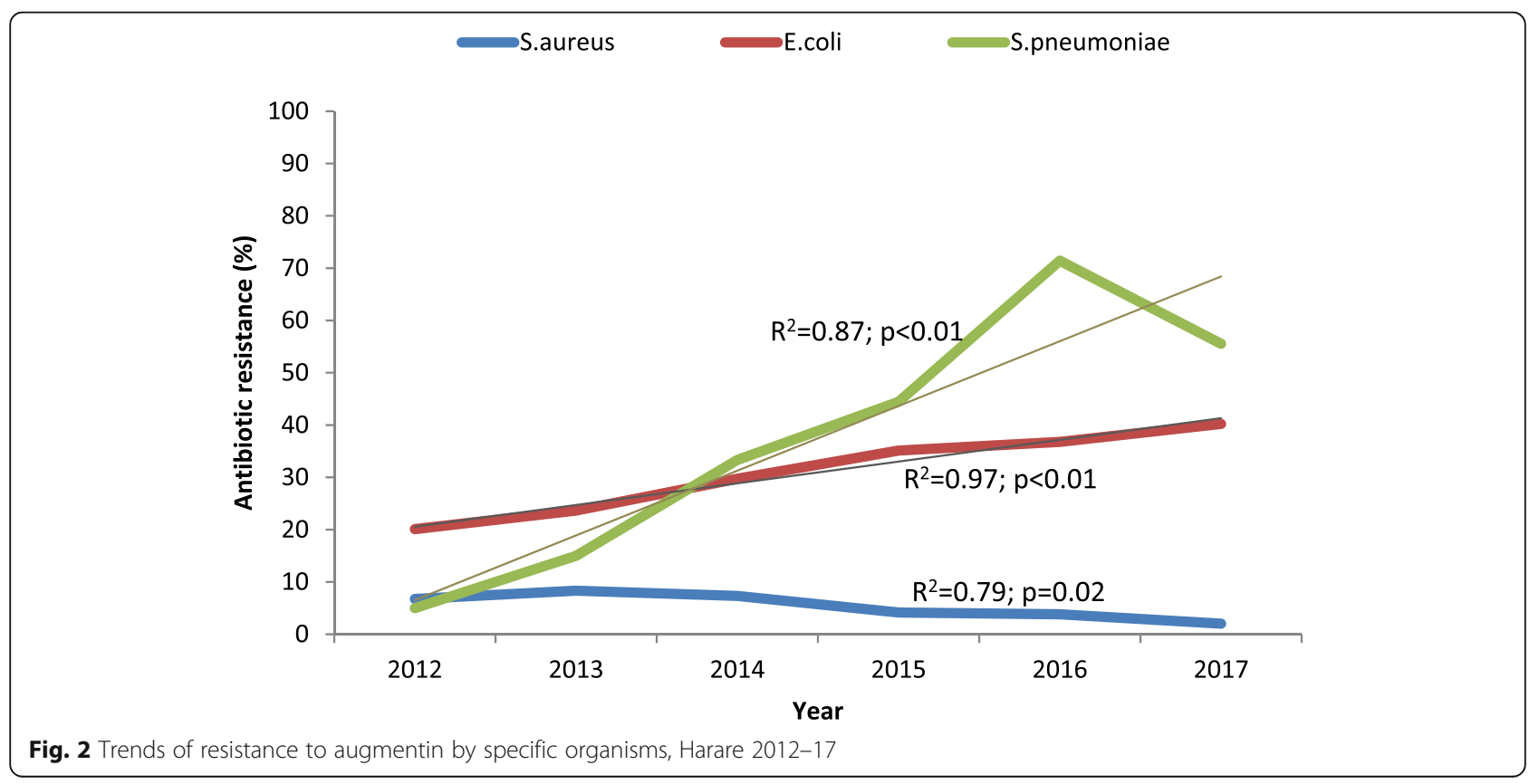



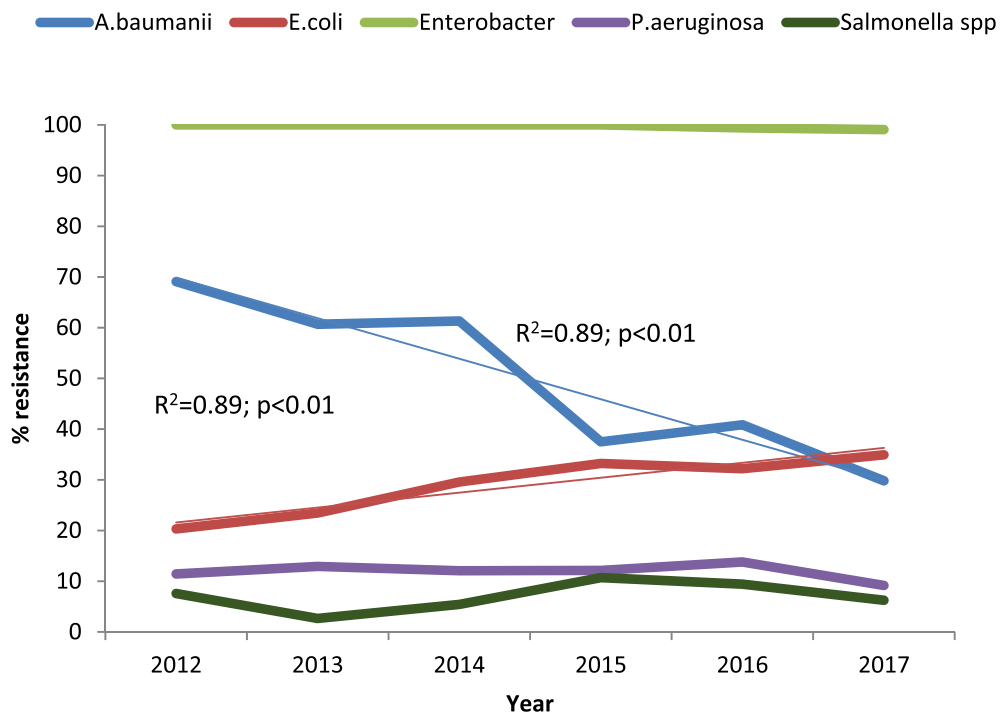

Fig. 3 Trends of resistance to cephalosporins by specific organisms, Harare 2012-17

ceftriaxone, benzyl penicillin, cloxacillin, amoxicillin and ciprofloxacin were the most prescribed antibiotics in Zimbabwe [11]. There were high levels of resistance to these antibiotics, consistent with literature which states that the more an antibiotic is used, the more the bacteria can develop resistance against it [12]. Resistance to commonly used antibiotics increases hospital admission time due to longer duration of illness. Also, the patients would require additional tests and would use more expensive drugs for treatment resulting in higher costs being incurred by the patients, their families and the nation's healthcare system [13]. The increasing resistance rates to last line antibiotics are very worrisome and may lead to the spread of life-threatening infections especially in hospitals [14].

Antimicrobial resistance rates to augmentin and cephalosporins (though much lower than amoxicillin and penicillin) were increasing significantly over time. The increases could be due to a rise in their use as clinicians avoid the highly resisted amoxicillin and penicillin.

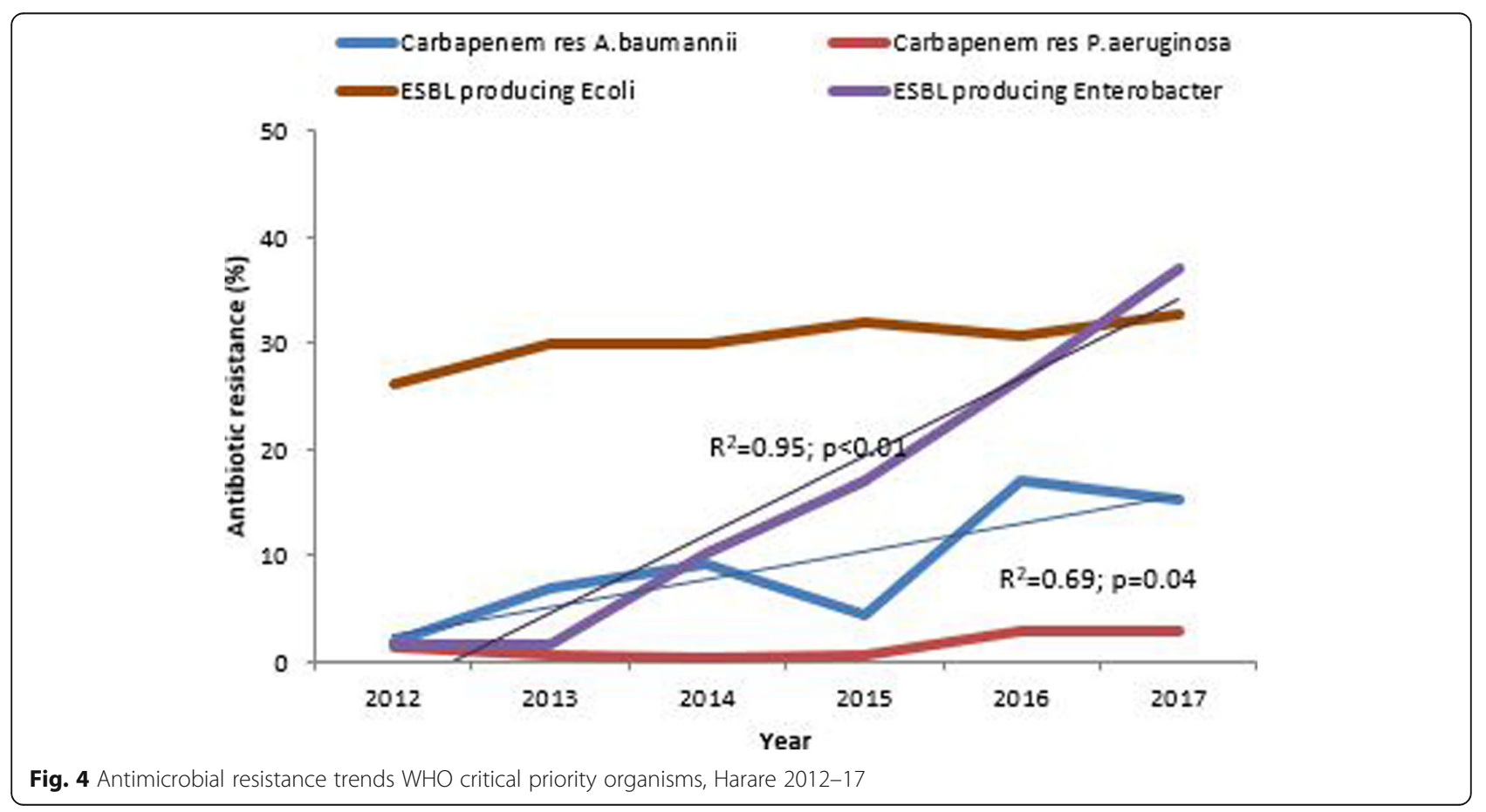


-MRSA Fluoroquinolone-res Salmonella Fluoroquinolone-res Campylobacter

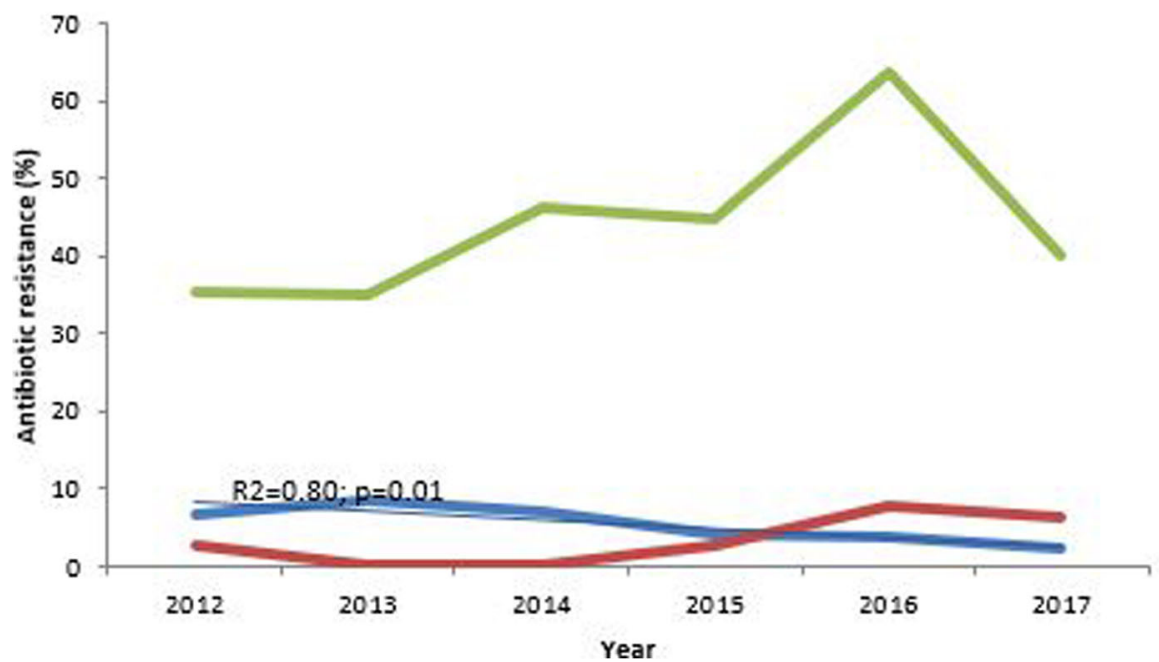

Fig. 5 Antimicrobial resistance trends WHO high priority organisms, Harare 2012-17

Increasing resistance to 3rd generation cephalosporins (e.g., ceftriaxone) has also been reported in countries like Korea where it was attributed to the spread of extended spectrum beta-lactamase producing bacteria [15]. Bacteria, especially Enterobacteriacae produce enzymes known as beta-lactamases which breakdown the beta-lactam rings in antibiotics like penicillin and amoxicillin, rendering the antibiotics useless against infections [16]. Our study reveals statistically significant increases in the prevalence of extended-spectrum betalactamase (ESBL) producing Enterobacteriaceae. Magwenzi et al. 2017 reported ESBL carriage in 52\% of patients before hospital admission, suggesting endemic ESBL carriage in Harare [17]. Other authors have explained the increasing prevalence of ESBL producing Enterobacteriaceae in multiple regions as representing the global expansion of ESBL-producing clones [18].

ESBL producing bacteria are multi-drug resistant (MDR), and this contributes to the high rates of AMR to B-lactams (e.g., penicillin, amoxicillin and ceftriaxone) by Gram-negative bacteria in this study. Treatment of ESBL producing bacterial infections with antibiotics that act as weak labile inducers (e.g., ampicillin and other Blactams) is clinically inappropriate. Drugs of choice for such infections are usually combinations of 4th generation cephalosporins (e.g., cefepime) plus an aminoglycoside which generally cost more than first-line antibiotics [19].

From the study findings, carbapenem resistance by Enterobacteriaceae was very low (i.e., < 1\%) throughout the 6 years in this study. The findings are consistent with Magwenzi et al. 2017 who reported a low prevalence of carbapenem-resistant Enterobacteriaceae of 1\% in Harare
[17]. Carbapenems are therefore a treatment of choice for ESBL positive infections. However, the use of carbapenems is costly especially for low-income countries like Zimbabwe which cannot afford extensive usage of these drugs in public health settings. Therefore, measures need to be put in place to decrease the carriage of ESBL producing bacteria in our population.

The results revealed an emergence of carbapenem-resistant $A$. baumannii and $P$. aeruginosa. These organisms are common causes of hospital-acquired infections and are usually multi-drug resistant. This increase in resistance may be due to increased carbapenem use in the treatment of multi-drug resistant infections by specialists in critical care settings, especially in the private sector. Increasing resistance to carbapenems has also been reported in South Africa where possible endemicity was suspected [20, 21]. Carbapenem-resistant organisms are critical priority organisms which are difficult to treat and cause serious infections which may lead to death. The mechanisms of resistance to carbapenems include carbapenemases production, efflux pumps and porin loss $[22,23]$. The emergence of carbapenem resistance coincides with a decreased resistance to cephalosporins by P.aeruginosa and A. baumannii in this study. The decrease in resistance to cephalosporins is probably due to a shift in selective pressure as carbapenems have become empirical treatment for $A$. baumannii and P. aeruginsa infections in critical care settings.

There was a decrease in methicillin-resistant Staphylococcus aureus (MRSA) over the 6 years. The results are consistent with findings from South Africa where MRSA prevalence declined from 36 to 24\% between 2006 and 
2011 but contrary to findings in Tunisia where it was increasing [24]. However, MRSA rates are much lower in our study than in South Africa. Some explanations potentially account for this observation, the simplest being possible improvements in infection prevention and control practices [25]. Another explanation is a shift in selective pressures away from beta-lactam therapy for staphylococcal infections causing the resistant organisms to be replaced by susceptible ones. Similar trends of declining MRSA prevalence have been reported in USA and Canada [26, 27]. However, the declines in MRSA rates have been attributed to shifts in epidemic strains rather than improved infection control measures.

An increasing trend was seen in fluoroquinolone resistance by Salmonella spp. and Campylobacter spp. According to the 2011 guidelines for the management of typhoid fever, ciprofloxacin is the drug of choice over the traditional first-line drugs (i.e., chloramphenicol, ampicillin, amoxicillin or cotrimoxazole) [28]. This empirical use of ciprofloxacin is a plausible cause of the increased resistance. Mashe et al. 2016 reported a sharp increase in ciprofloxacin-resistant S. typhi. The resistance rates were much lower in the current study probably because all Salmonella species included and may have confounded the resistance rates of $S$. typhi [7]. If this increasing resistance trend persists, more effective, appropriate alternative medicines for the treatment of typhoid would have to be used and the treatment guidelines would need to be revised. The increase in fluoroquinolone resistant Campylobacter is consistent with Sproston et al. 2018 who found similar findings in the UK [29]. They attributed it to genetic mutations in the quinolone-resistant-determining regions and exchange of drug resistant bacteria between animals and humans through acquisition of qnr genes.

While we can explain some of these trends, there is a lot of genetic dynamism involved in antimicrobial resistance. Also, some resistance genes are acquired from bacteria of a different genus while other resistant strains come from other parts of the world through human migration.

The study had limitations since it was a retrospective study. It could not be ascertained whether the infections were community acquired or nosocomial or whether resistance was primary or secondary. Hence the AMR rates were generalised to the whole study population. Also, the sample comprised approximately $85 \%$ specimens from private institutions, therefore, might not adequately represent resistance rates in public health settings.

\section{Conclusions}

From the results of this study, it can be concluded that there is a high burden of AMR to commonly used antibiotics like amoxicillin, penicillin, augmentin, ciprofloxacin and cotrimoxazole. Also, there is an increase in priority organisms which include carbapenem-resistant $A$. baumannii, carbapenem-resistant $P$. aeruginosa, fluoroquinolone-resistant Salmonella, and ESBL producing Enterobacteriaceae. However, the following organisms are not a major problem in Harare; carbapenem-resistant Enterobacteriacae, vancomycin-resistant Enterococci, vancomycin-resistant $S$. aureus and 3rd generation cephalosporin-resistant N. gonorrhoea.

Development of a robust nationwide surveillance is recommended for monitoring priority organisms so that they are identified and treated before they spread. The antibiotics needed to treat multi-drug resistant infections (e.g., vancomycin and colistin) are too expensive for resource-limited countries, leaving infection prevention as the best strategy for curbing AMR. The use of vaccination for diseases like S. typhi, where vaccines are available should be implemented as a prevention method. Further studies should be done, to compare or relate antibiotic prescribing practices and subsequent AMR patterns in Harare. We also recommend comparisons of AMR prevalence in hospital-acquired-infections (HAIs) and community-acquired infections so that interventions may be focussed on appropriately.

\section{Abbreviations \\ AMR: Antimicrobial resistance; ARMSNET: Antimicrobial Resistance Surveillance Network; CDC: Centres for Disease Control; ESBL: Extended spectrum B-lactamase; HAl: Hospital-acquired infection; MDR: Multi-drug resistant; MRSA: Methicillin-resistant Staphylococcus aureus; SANAS: South African National Accreditation System; SDG: Sustainable development goal; WHO: World Health Organisation}

\section{Acknowledgements}

We would like to express our sincere gratitude to the staff at Lancet Clinical Laboratories Harare, Master in Public Health colleagues, Department of

Community Medicine, University of Zimbabwe and the Health Studies Office, Zimbabwe for all their support. Special thanks go to my family for the support throughout the study.

\section{Authors' contributions}

MM, NN, DB: conception and design of study, analysis and interpretation of data, drafting the manuscript. GS, NG, TJ, PN MT: conception and design of study and critically reviewing the manuscript for important intellectual content. All authors read and approved the final manuscript for publication.

\section{Funding}

Not applicable

\section{Availability of data and materials}

The data that support the findings of this study are available from Lancet Clinical laboratories, but restrictions apply to the availability of these data. Data are however available from the authors upon reasonable request and with Lancet Clinical laboratory.

\section{Ethics approval and consent to participate}

This study was approved by Lancet Clinical laboratory management and the Health Studies Office in the Ministry of Health Institutional Review Board. The board waived the need for informed consent due to the retrospective nature of the study, however we did not use patients' information in this study as it was anonymised by use of patient account numbers. Data was kept safe and confidential and only used for this study. Administrative permission to access data was requested through the laboratory manager of 
Lancet Clinical laboratories Zimbabwe and granted by the Consultant Microbiologist and Information Systems Consultant at Lancet South Africa.

\section{Consent for publication}

Not Applicable

\section{Competing interests}

The authors declare that they have no competing interests.

\section{Author details}

'Department of Community Medicine, University of Zimbabwe, Harare, Zimbabwe. ${ }^{2}$ African Society of Laboratory Medicine, Addis Ababa, Ethiopia. ${ }^{3}$ Africa Centres for Disease Control and Prevention, Addis Ababa, Ethiopia. ${ }^{4}$ Global Health Solutions, Atlanta, GA, USA.

Received: 8 January 2019 Accepted: 17 July 2019

Published online: 27 August 2019

\section{References}

1. Crowther-Gibson P, Govender N, Lewis DA, Bamford C, Brink A, von Gottberg A, et al. Part IV. Human infections and antibiotic resistance. S Afr Med J. 2011 Jul 28;101(8 Pt 2):567-78.

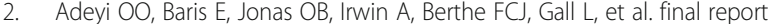
[Internet]. The World Bank; 2017 [cited 2018 May 17] p. 1-172. Report No.: 114679. Available from: http://documents.worldbank.org/curated/ en/323311493396993758/final-report

3. $\mathrm{WHO} \mid$ Antimicrobial resistance: global report on surveillance 2014 [Internet]. WHO. [cited 2018 May 17]. Available from: http://www.who.int/ drugresistance/documents/surveillancereport/en/

4. WHO ANTIBACTERIAL AGENTS IN CLINICAL DEVELOPMENT [Internet]. WHO. [cited 2018 May 17]. Available from: http://www.who.int/medicines/areas/ rational_use/antibacterial_agents_clinical_development/en/

5. Africa CDC Antimicrobial Resistance Surveillance Network Launched during a Special Edition of ACDx Course [Internet]. Mérieux Foundation. 2013 [cited 2018 May 29]. Available from: https://www.fondation-merieux.org/en/ news/38-students-from-20-countries-took-our-advanced-course-ondiagnostics-acdX/

6. Mbanga J, Dube $\mathrm{S}$, Munyanduki $\mathrm{H}$. Prevalence and drug resistance in bacteria of the urinary tract infections in Bulawayo province, Zimbabwe East. Afr J Public Health. 2010;7(3):229-32.

7. Mashe T, Mugabe M, Tarupiwa A, Stray-Pedersen B, Mbanga J. Antibiotic resistance trends of Salmonella typhi in Zimbabwe (2012 - 2016). In 2016.

8. Metcalfe JZ, Makumbirofa S, Makamure B, Sandy C, Bara W, Mungofa S, et al. Drug-resistant tuberculosis in high-risk groups, Zimbabwe. Emerg Infect Dis. 2014 Jan;20(1):135-7.

9. Sustainable development goals - United Nations [Internet]. United Nations Sustainable Development. [cited 2018 May 17]. Available from: https://www. un.org/sustainabledevelopment/sustainable-development-goals/

10. Population Census Vital | Zimbabwe National Statistics [Internet]. [cited 2018 Jun 12]. Available from: http://www.zimstat.co.zw/population-census-vital.

11. SITUATION-ANALYSIS-OF-ANTIMICROBIAL-USE-AND-RESISTANCE-INHUMANS-AND-ANIMALS-IN-ZIMBABWE-1.pdf [Internet]. [cited 2018 May 17]. Available from: https://cddep.org/wp-content/uploads/2017/10/SITUATIONANALYSIS-OF-ANTIMICROBIAL-USE-AND-RESISTANCE-IN-HUMANS-ANDANIMALS-IN-ZIMBABWE-1.pdf

12. Llor C, Bjerrum L. Antimicrobial resistance: risk associated with antibiotic overuse and initiatives to reduce the problem. Ther Adv Drug Saf. 2014;5(6):229-41.

13. Ventola CL. The antibiotic resistance crisis. P T. 2015:40(4):277-83.

14. Antimicrobial resistance [Internet]. World Health Organization. [cited 2018 May 29]. Available from: http://www.who.int/news-room/fact-sheets/detail/ antimicrobial-resistance

15. Kim D, Ahn JY, Lee $\mathrm{CH}$, Jang SJ, Lee $H$, Yong $\mathrm{D}$, et al. Increasing resistance to extended-Spectrum Cephalosporins, fluoroquinolone, and Carbapenem in gram-negative bacilli and the emergence of Carbapenem nonsusceptibility in Klebsiella pneumoniae: analysis of Korean antimicrobial resistance monitoring system (KARMS) data from 2013 to 2015. Ann Lab Med. 2017:37(3):231-9.

16. Pitout JDD, Laupland KB. Extended-spectrum beta-lactamase-producing Enterobacteriaceae: an emerging public-health concern. Lancet Infect Dis. 2008;8(3):159-66.
17. Magwenzi MT, Gudza-Mugabe M, Mujuru HA, Dangarembizi-Bwakura M Robertson V, Aiken AM. Carriage of antibiotic-resistant Enterobacteriaceae in hospitalised children in tertiary hospitals in Harare, Zimbabwe. Antimicrob Resist Infect Control. 2017:6:10.

18. Armand-Lefèvre L, Andremont A, Ruppé E. Travel and acquisition of multidrug-resistant Enterobacteriaceae. Med Mal Infect. 2018;48(7):431-41.

19. Piccirillo JF, Mager DE, Frisse ME, Brophy RH, Goggin A. Impact of first-line vs second-line antibiotics for the treatment of acute uncomplicated sinusitis. JAMA. 2001;286(15):1849-56.

20. Osei Sekyere J. Current State of Resistance to Antibiotics of Last-Resort in South Africa: A Review from a Public Health Perspective. Front Public Health [Internet]. 2016 Sep 30 [cited 2018 May 18];4. Available from: https://www. ncbi.n/m.nih.gov/pmc/articles/PMC5042966/

21. Brink A, Moolman J, da Silva MC, Botha M. National antibiotic surveillance forum. Antimicrobial susceptibility profile of selected bacteraemic pathogens from private institutions in South Africa. S Afr Med J. 2007;97(4):273-9.

22. WHO publishes list of bacteria for which new antibiotics are urgently needed [Internet]. World Health Organization. [cited 2018 May 29]. Available from: http://www.who.int/news-room/detail/27-02-2017-who-publishes-listof-bacteria-for-which-new-antibiotics-are-urgently-needed

23. Carbapenem Resistance: A Review [Internet]. [cited 2019 Apr 18]. Available from: https://www.ncbi.nlm.nih.gov/pmc/articles/PMC5872158/.

24. Falagas ME, Karageorgopoulos DE, Leptidis J, Korbila IP. MRSA in Africa: filling the global map of antimicrobial resistance. PLoS One. 2013;8(7):e68024.

25. Evans ME, Kralovic SM, Simbartl LA, Jain R, Roselle GA. Eight years of decreased methicillin-resistant Staphylococcus aureus health care-associated infections associated with a veterans affairs prevention initiative. Am J Infect Control. 2017:45(1):13-6.

26. Lagacé-Wiens PRS, Adam HJ, Low DE, Blondeau JM, Baxter MR, Denisuik AJ, et al. Trends in antibiotic resistance over time among pathogens from Canadian hospitals: results of the CANWARD study 2007-11. J Antimicrob Chemother. 2013;68(suppl_1):i23-9.

27. Epidemiology of Staphylococcus aureus Blood and Skin and Soft Tissue Infections in the US Military Health System, 2005-2010 | Critical Care Medicine | JAMA | JAMA Network [Internet]. [cited 2018 May 22]. Available from: https://jamanetwork.com/journals/jama/fullarticle/1212307

28. Guidelines for the Management of Typhoid Fever. Zimbabwe, 2011 [Internet]. [cited 2018 May 18]. Available from: http://apps.who.int/ medicinedocs/en/d/Js20994en/.

29. Microbiology Society Journals | Trends in fluoroquinolone resistance in Campylobacter [Internet]. [cited 2019 Apr 18]. Available from: https://mgen. microbiologyresearch.org/content/journal/mgen/10.1099/mgen.0.000198.

\section{Publisher's Note}

Springer Nature remains neutral with regard to jurisdictional claims in published maps and institutional affiliations.

Ready to submit your research? Choose BMC and benefit from:

- fast, convenient online submission

- thorough peer review by experienced researchers in your field

- rapid publication on acceptance

- support for research data, including large and complex data types

- gold Open Access which fosters wider collaboration and increased citations

- maximum visibility for your research: over $100 \mathrm{M}$ website views per year

At $\mathrm{BMC}$, research is always in progress.

Learn more biomedcentral.com/submission 